\title{
A Comparative Study of Different Metaheuristic Algorithms for Designing Harmonics Estimator
}

\author{
Aishwarya Mehta ${ }^{1}$, Jitesh Jangid ${ }^{1}$, Akash Saxena ${ }^{1}$, S.L. Surana ${ }^{1}$, Shalini Shekhawat ${ }^{2}$ \\ ${ }^{1}$ Department of Electrical Engineering, Swami Keshvanand Institute of Technology, Management \& \\ Gramothan, Jaipur-302017 (INDIA) \\ ${ }^{2}$ Department of Mathematics, Swami Keshvanand Institute of Technology, Management \& Gramothan, \\ Jaipur-302017 (INDIA) \\ Email: aishu.sharma.0786@gmail.com,jj90946@gmail.com, aakash.saxena@ hotmail.com, \\ sls@skit.ac.in, shekhawatshalini17@gmail.com \\ Received 16.03.2021, received in revised form 20.03.2021, accepted 20.03.2021
}

\begin{abstract}
In the modern power system, the power quality issues are prominent. For dealing with power quality issues, harmonic mitigation technologies are inevitable. Hence, design of Harmonic Estimator has become more important aspect because power quality is directly related to customer satisfaction and electricity tariffs. Nature-inspired algorithms have been applied by researchers to develop harmonic estimators. In this paper, harmonic phase and amplitude components are estimated by Artificial Bee Colony (ABC), Teaching- Learning Based Optimization (TLBO), Grey Wolf Optimization (GWO), Sine Cosine Algorithm (SCA), Moth Flame Optimizer (MFO), and Atom Search Optimization (ASO). All the mentioned algorithms are tested on the two standard design problems and comparative analysis of the optimization performance of these algorithms is presented.
\end{abstract}

Keywords- Fast Fourier transform, Wavelet Transform, Kalman Filter, Adaptive Kalman Filter, Metaheuristics.

\section{INTRODUCTION}

Harmonics play a vital role in the electrical power system network. Harmonics deteriorate current and voltage waveforms in the power system network. These deteriorated waveforms contain multiple of the fundamental frequency i.e. $50 \mathrm{~Hz}$. These distortions in the waveforms introduced by nonlinear switching devices like power converters, variable-frequency drives, lighting devices, etc. These power electronics devices are used to convert power from AC to DC and vice-versa and also filter out distortion due to over-voltage and voltage dip. The use of power electronics devices is rapidly increasing in daily life. These devices are the cause of harmonics which are classified into four categories which are listed below

- Sub- Harmonics [1]

- Inter-Harmonics [2]

- Odd -Harmonics [3]

- Even- Harmonics [3]

Eddy Current Loss, Skin Effect, Ferranti Effect, heating problem are the adverse effects of harmonics. Harmonics decrease the life span of power equipment, reduction in motor torque and also distort the information which is carried by power communication lines. To control the flow of harmonics in the electrical power system network it is necessary to design filters. Filters are used to filter-out the harmonics. Mainly power system network uses the following two types of filters

- Passive Filters [4]

- Active Filters [4]

To design an effective filter it is necessary to get accurate values of phase and amplitude components of power harmonics. For accurate estimation, harmonic estimators are used.

Harmonic estimators provide the accurate estimation of power harmonics parameters which help to design an appropriate filter.

In the last few years, different methods are used to estimate harmonic components. Fast Fourier Transform (FFT) is used in [5], but in the presence of inter-harmonics [6] components, FFT fails to exactly estimate the power harmonics components. Wavelet Transform (WT) [7] is used to estimate different frequencies of power harmonics components. In WT filter banks are used, for higher order frequency signals the number of filter banks also increases which takes more time to estimate the power harmonic components. In this context Kalman Filter (KF) [8] is also used for accurate estimation of power harmonics components, which is a recursive type approach that uses state-space modelling approach. In the concept of KF, it is implemented into various forms like Ensemble Kalman Filter [9], Extended Real Modal of Kalman Filter [10], Adaptive Kalman Filter [11], etc. In this technique, state-space modelling is a difficult process. From the above discussed methods, it is difficult to make exact estimate of power harmonics component for real-time monitoring. So the researchers tried to avoid mathematical approach and adapted the newly developed meta-heuristic approach which gets inspiration from nature and provide better solution in comparison to mathematical approach. Mathematical approach is time taking when the number of harmonic components increase while the meta-heuristic approach is less time-consuming. Metaheuristic 
approaches have the ability to come out from local optima's and are capable to find global optimum.

Meta-heuristic approaches get inspiration from nature, physics laws, chemical reactions, molecular dynamics, human activities, etc. Example of metaheuristic approaches are Differential Search Algorithm (DSA) [12], Binary Bat Algorithm (BBA) [13], Big Bang-Big Crunch (BB-BC) Algorithm [14], Spider Monkey Optimization (SMO) [15] etc. The objective of this paper is to provide a comparison of harmonic estimators using different metaheuristic methods which are Grey Wolf Optimizer (GWO), [16], Sine Cosine Algorithm (SCA) [17], Atom Search Optimization (ASO)[18], Moth Flame Optimizer (MFO) [19], Artificial Bee Colony (ABC) [20], and TeachingLearning Based Optimization (TLBO) [21].

\subsection{Layout of paper}

In the first section, problem is introduced. After that in the second section mathematical formulation of the problem is expressed. In the third section different meta-heuristic approaches are presented briefly. Fourth section comprises of harmonic estimator case studies using analytical analysis. In the last section, we concluded the paper.

\section{PROBLEM FORMULATION}

In the introduction, it is stated that harmonics create many problems and also distort the current and voltage waveforms. So, it is important to estimate the exact values of harmonic contents in the current and voltage waveforms. Normally voltage and current waveforms are written as

$$
P(t)=\sum_{i=1}^{I} M_{i} \sin \left(w_{i} t+\phi_{i}\right)+M_{D C} \exp \left(-\theta_{D C} t\right)+U(t)
$$

where, order of power harmonics represented by $I, w_{i}$ is angular frequency which is estimated by $\omega_{i}=i 2 \pi f_{\text {fun }}, f_{\text {fun }}$ is known as fundamental frequency. Additive White Gaussian Noise (AWGN) is represented by $U(t) \cdot M_{D C} \exp \left(-\theta_{D C} t\right)$ is used to denote DC component's exponential decaying term.

Now the above voltage and current waves are sampled and Taylor series expansion [22] is applied. After these modifications equation can be written as

$$
\begin{array}{r}
P(a)=\sum_{i=1}^{I}\left[M_{i} \sin \left(w_{i} a T_{S}\right) \cos \left(\phi_{i}\right)+M_{i} \cos \left(w_{i} a T_{s}\right) \sin \left(\phi_{i}\right)\right] \\
+M_{D C}-M_{D C} \exp \left(-\phi_{D C} a T_{S}\right)+U(a)
\end{array}
$$

We, then, convert the above equation into parametric form which is expressed as

$$
P(n)=D(n) \phi(n)
$$

Here $D(n)$ is measured by following equation

$$
\begin{gathered}
D(n)=\left[\operatorname { s i n } ( w _ { 1 } a T _ { S } ) \operatorname { c o s } \left(w_{1} a T_{S} \ldots . \sin \left(w_{i} a T_{S}\right)\right.\right. \\
\left.\left.\cos \left(w_{i} a T_{S}\right) 1-a T_{s}\right)\right]^{T}
\end{gathered}
$$

Now, all the unknown parameters are estimated by the expression

$$
\begin{aligned}
\phi(n)=\left[M_{1} \sin \left(\phi_{1}\right) \cos \left(\phi_{1}\right) \ldots . M_{i} \sin \left(\phi_{k}\right)\right. \\
\\
\left.\cos \left(\phi_{k}\right) \ldots \ldots M_{D C} \ldots . \phi_{D C}\right]^{T}
\end{aligned}
$$

The objective function of harmonic estimation problem is described as

$$
O=\operatorname{Min}\left(\sum_{n=1}^{N}\left(P_{n}-P_{n e s t}\right)^{2}\right)
$$

Here, $\mathrm{O}$ is used to represent the objective function, $P_{n}$ is original waveform of the problem while $P_{n e s t}$ is measured wave form.

\section{COMPARISON OF DIFFERENT ALGORITHMS}

In this section different algorithms (GWO, SCA, ATOM, MFO, ABC, and TLBO) are compared with each other. To make a trustworthy comparison we test these algorithms on the standard benchmark test functions. The algorithms which help in this comparison are well described as follows

\subsection{Artificial Bee Colony}

Artificial Bee Colony (ABC) [20] algorithm is proposed by Karaboga et. al. in 2005. ABC algorithm is inspired by the social behaviour and sharing of information process of Bees. In a hive, a large number of bees live in a group. These bees are categorized into three groups, first one is the employed bees group, the second one is the onlooker bees group and last is scout bees group. Employed bees are half of the total number of bees in hives and search for food in nature. Food quality depends on the nectar amount, when the honey bees find new location of food source then they forgot the previous location. Information collected by the employed bees is shared by onlooker bees. Onlooker bees are also half number of honey bees that are present in hive and waiting for the employed bees and get the information by employed bees. Scout bees help to find a new location of the food source. In this phenomena researcher inspired by the information sharing and working in the group process. The position update equation of $\mathrm{ABC}$ is written as

$$
v_{i j}=X_{i j}+\phi_{i j}\left(X_{i j}-X_{k j}\right)
$$

Where $X_{i j}$ represents location of food source and $\phi_{i j}\left(X_{i j}-X_{k j}\right)$ shows step size. 


\subsection{Teaching-Learning Based Optimization}

In 2010, R.V.Rao et. al. introduced TeachingLearning Based Optimization (TLBO) [21]. This algorithm represents a relation between educator and learner. In this process educator tries to give his/her own best, the learner also wants to get $100 \%$ given by the educator. Learner's understanding capability plays a vital role to get the knowledge which is provided by educator. To assess the learner, examination is conducted. This examination helps to find which learner acquires more knowledge and which educator is capable to deliver more knowledge to the learner. The position update equation of TLBO is written as

$$
Z_{\text {new }, c}=Z_{\text {old }, c}+\text { Difference } \text { Mean }_{c}
$$

Here $Z_{\text {old }, c}$ is existing function value and Difference Mean $_{c}$ is a difference between existing and new mean.

\subsection{Grey Wolf Optimization}

In 2014, Ali Mirjalili et al. proposed Grey Wolf Optimization (GWO) [16], which is inspired by the special behaviour of the grey wolf. In nature, grey wolves always live in groups and search for their food. To search their food, these wolves are divided into three small groups which are known as alpha wolves group, beta wolves group and omega wolves group. Alpha wolves group take a decision to provide the best solution to the algorithm and also maintains the discipline. All the group members also follow the decision of the alpha wolves which represents the leadership in the group. Beta wolves groups follow the instructions given by alpha wolves and these are subordinate wolves. While omega wolves are the last group which also help the group members to search for food. After searching process is finished, these wolves encircle the food (prey). After encircling the prey, grey wolves update their position with respect to prey. At last, these grey wolves attack the prey and hunted the prey. In this process, it is recognized that the position update process helps to find the best solution. The position update equation of GWO is written as

$$
\vec{Y}_{(t+1)}=\frac{\vec{Y}_{1}+\vec{Y}_{2}+\vec{Y}_{3}}{3}
$$

here $\vec{Y}_{1}, \vec{Y}_{2}$ and $\vec{Y}_{3}$ are positions of alpha, beta, and omega wolves respectively.

\subsection{Sine Cosine Algorithm}

The Sine-Cosine Algorithm (SCA) [17] was proposed in 2016 by Ali Miijalili et al. which is a mathematics dependent metaheuristic algorithm. This method uses a mathematical model approach which is based on the functions of sine and cosine. These candidate solutions are initially generated inside the solution space. These candidate solutions are regularly updates their solution value with respect to time. After getting the best solution algorithm is terminated. The position update equations of SCA are written as

$$
\begin{aligned}
& q_{x}^{t+1}=q_{x}^{t}+r_{1} \times \sin \left(r_{2}\right) *\left|r_{3} P_{x}^{t}-q_{x}^{t}\right| \\
& q_{x}^{t+1}=q_{x}^{t}+r_{1} \times \cos \left(r_{2}\right) *\left|r_{3} P_{x}^{t}-q_{x}^{t}\right|
\end{aligned}
$$

Where, $q_{x}^{t}$ is position update of recent solution of $x^{\text {th }}$ dimension $r_{1}, r_{2}$ and $r_{3}$ are the random numbers and $P_{x}^{t}$ indicates position of goal in $x^{\text {th }}$ dimension.

\subsection{Moth Flame Optimizer}

Moth Flame Optimizer algorithm (MFO) [19] is developed in 2015 by the Ali Mirjalili et al. almost all metaheuristic techniques get inspiration from nature. This algorithm uses a unique orientation phenomenon which is known as transverse orientation. In this algorithm moth tries to update its position when the flame updates its position. This position update method helps to find the best solution by forgetting the worst solution. The position update equation of MFO is written as

$$
M_{y}=S_{f}\left(M_{y}, F_{z}\right) z^{t h}
$$

where, $S_{f}$ represents the spiral function, $M_{y}$ represents the $y^{\text {th }}$ moth, and $F_{z}$ represents the $z^{\text {th }}$ flame.

\subsection{Atom Search Optimization}

Atom Search Optimization (ASO) [18] is a newly developed algorithm that is proposed by Zhao et al in 2019. This algorithm gets inspiration from molecular dynamics. Molecular dynamics is used in different fields of science like chemistry, physics, mechanics, etc. In this algorithm, each atom tries to update its fitness by attracting other atoms. The velocity and position update equations of ASO is written as

$$
\begin{gathered}
V_{i}^{d}(t+1)=\text { random }_{i}^{d}(t)+a_{i}^{d}(t) \\
X_{i}^{d}(t+1)=X_{i}^{d}(t)+V_{i}^{d}(t+1)
\end{gathered}
$$

$V_{i}^{d}(t)=$ Velocity of $i^{t h}$ atom in dimension ' $\mathrm{d}$ ' at time ' $\mathrm{t}$ '

$a_{i}^{d}(t)=$ Acceleration of $i^{t h}$ atom in dimension ' $\mathrm{d}$ ' at time ' $\mathrm{t}$ '

$X_{i}^{d}(t)=\mathrm{X}$ is position of $i^{t h}$ atom in dimension ' $\mathrm{d}$ ' at time ' $\mathrm{t}$ '

$V_{i}^{d}(t+1)=$ Velocity of $i^{t h}$ atom in dimension ' $\mathrm{d}$ ' at time ' $(\mathrm{t}+1)$ '

\section{DESIGN PROBLEMS FOR HARMONIC ESTIMATOR}

In this section, we present to develop a harmonic estimator that provides an exact estimation of phase and amplitude components of power harmonics. For authentication of harmonic estimator design, two design problems have been considered which are taken from [22]. This simulation work is compiled 
on MAT-LAB 2015a on Intel Core i5 8th generation processor with $8 \mathrm{~GB}$ of ram. In this simulation work, a fair comparison is done while taking same parameters in account which is the number of search agents (30) and the maximum number of iteration (500).

\subsection{Design Problem-1}

For design problem-1 a waveform is used which is made up of the fundamental, $3^{\text {rd }}, 5^{\text {th }}, 7^{\text {th }}$ and $11^{\text {th }}$ harmonics. The objective of different designed estimators is to create a replica of this waveform and estimate the phase and amplitude of each harmonic component. This estimation should be done in such a manner so that the expression (6) can be minimized. This design problem-1 is mathematically expressed as $X_{1}(a)$.

To check the fitness value of problem-1, we simulate the algorithms for 20 independent runs and calculate four analytical attributes of fitness values of objective function which are listed below

1. Average Value (Mean)

2. Maximum Value (Max)

3. Minimum Value (Min)
4. Standard Deviation (SD)

The design problem- 1 is mathematically expressed as

$$
\begin{aligned}
X_{1}(a)= & \frac{3}{2} \times \sin \left(2 \pi f^{(1)} c+80\right)+\frac{1}{2} \\
& \times \sin \left(2 \pi f^{(3)} c+60\right)+\frac{1}{5} \times \sin \left(2 \pi f^{(5)} c+45\right) \\
& +\frac{3}{20} \times \sin \left(2 \pi f^{(7)} c+36\right)+\frac{1}{10} \\
& \times \sin \left(2 \pi f^{(11)} c+30\right)+\frac{1}{2} \times \exp (-5 c)+\sigma
\end{aligned}
$$

After calculating these analytical attributes, these values are depicted in table 1 . From table 1 it is concluded that MFO provides optimal values for mean, standard deviation, and maximum attribute in comparison to $\mathrm{ABC}, \mathrm{GWO}, \mathrm{SCA}, \mathrm{MFO}, \mathrm{ASO}$ algorithms.

Table 1 Result comparison of applied algorithms for Problem 1.

\begin{tabular}{|c|c|c|c|c|}
\hline \multicolumn{5}{|c|}{ Estimated Results of Case-1 } \\
\hline Waveforms & \multicolumn{4}{c|}{ X(a) } \\
\hline Parameters & Mean & Max & Min & SD \\
\hline GWO & $1.3649 \mathrm{E}-06$ & $3.4825 \mathrm{E}-06$ & $2.5370 \mathrm{E}-07$ & $8.5093 \mathrm{E}-07$ \\
\hline ABC & $3.2285 \mathrm{E}-17$ & $1.2846 \mathrm{E}-16$ & $2.2124 \mathrm{E}-18$ & $4.3025 \mathrm{E}-17$ \\
\hline SCA & $4.0335 \mathrm{E}-05$ & $6.3803 \mathrm{E}-05$ & $1.4048 \mathrm{E}-05$ & $1.6515 \mathrm{E}-05$ \\
\hline MFO & $0.0000 \mathrm{E}+00$ & $0.0000 \mathrm{E}+00$ & $0.0000 \mathrm{E}+00$ & $0.0000 \mathrm{E}+00$ \\
\hline TLBO & $7.4698 \mathrm{E}-31$ & $5.2578 \mathrm{E}-30$ & $0.0000 \mathrm{E}+00$ & $1.6191 \mathrm{E}-30$ \\
\hline WOA & $6.4479 \mathrm{E}-06$ & $1.2009 \mathrm{E}-05$ & $1.6571 \mathrm{E}-07$ & $3.8570 \mathrm{E}-06$ \\
\hline
\end{tabular}

Table 2 Parameters Analysis of Problem-1

\begin{tabular}{|c|c|c|c|c|c|c|}
\hline \multicolumn{7}{|c|}{ Parameter's Analysis of Problem-1 } \\
\hline Waveforms & Parameters & Fun & 3rd & 5th & 7th & 11th \\
\hline \multirow{2}{*}{$\begin{array}{c}\text { Actual } \\
\text { Waveform }\end{array}$} & $\mathbf{F}(\mathbf{H z})$ & 50 & 150 & 250 & 350 & 550 \\
\cline { 2 - 7 } & $\mathbf{A}(\mathbf{V})$ & 1.5 & 0.5 & 0.2 & 0.15 & 0.1 \\
\cline { 2 - 7 } & $\mathbf{P}(\mathbf{d e g})$. & 80 & 60 & 45 & 36 & 30 \\
\hline \multirow{2}{*}{ ABC } & $\mathbf{A}(\mathbf{V})$ & 1.5000 & 0.5000 & 0.2000 & 0.1500 & 0.1000 \\
\cline { 2 - 7 } & $\mathbf{P}(\mathbf{d e g})$. & 80.0000 & 60.0000 & 45.0000 & 36.0000 & 30.0000 \\
\hline \multirow{2}{*}{ TLBO } & $\mathbf{A}(\mathbf{V})$ & 1.5000 & 0.5000 & 0.2000 & 0.1500 & 0.1000 \\
\cline { 2 - 7 } & $\mathbf{P}(\mathbf{d e g})$. & 80.0000 & 60.0000 & 45.0000 & 36.0000 & 30.0000 \\
\hline \multirow{2}{*}{ GWO } & $\mathbf{A}(\mathbf{V})$ & 1.5000 & 0.5000 & 0.1998 & 0.1503 & 0.0999 \\
\cline { 2 - 7 } & $\mathbf{P}(\mathbf{d e g})$. & 79.9968 & 59.9944 & 44.9740 & 35.7391 & 30.2121 \\
\hline \multirow{2}{*}{ SCA } & $\mathbf{A}(\mathbf{V})$ & 1.5001 & 0.5000 & 0.1989 & 0.1506 & 0.1003 \\
\cline { 2 - 7 } & $\mathbf{P}(\mathbf{d e g})$. & 79.9945 & 59.8459 & 44.9012 & 35.4202 & 29.7687 \\
\hline \multirow{2}{*}{ MFO } & $\mathbf{A}(\mathbf{V})$ & 1.5000 & 0.5000 & 0.2000 & 0.1500 & 0.1000 \\
\cline { 2 - 7 } & $\mathbf{P}(\mathbf{d e g})$. & 80.0000 & 60.0000 & 45.0000 & 36.0000 & 30.0000 \\
\hline \multirow{2}{*}{ ASO } & $\mathbf{A}(\mathbf{V})$ & 1.5006 & 0.5002 & 0.1984 & 0.1501 & 0.1000 \\
\cline { 2 - 7 } & $\mathbf{P}(\mathbf{d e g})$. & 79.9998 & 59.8152 & 45.3137 & 35.6885 & 30.1384 \\
\hline
\end{tabular}


Table $3 \%$ Error Analysis of Problem-1

\begin{tabular}{|c|c|c|c|c|c|c|}
\hline \multirow{3}{*}{ Signal's } & Parameters & Fun & 3rd & \multirow{2}{*}{ 5th } & \multirow{2}{*}{ 7th } & \multirow{2}{*}{ 11th } \\
& & & & & \\
\multirow{3}{*}{$\begin{array}{c}\text { Actual } \\
\text { Signal }\end{array}$} & F (Hz) & 50 & 150 & 250 & 350 & 550 \\
\cline { 2 - 7 } & A (V) & 1.5 & 0.5 & 0.2 & 0.15 & 36 \\
\hline \multirow{2}{*}{ GWO } & \% Error (A) & $2.5178 \mathrm{E}-04$ & $4.1375 \mathrm{E}-03$ & $1.1553 \mathrm{E}-01$ & $1.9983 \mathrm{E}-01$ & $1.2421 \mathrm{E}-01$ \\
\cline { 2 - 7 } & \% Error (P) & $3.9407 \mathrm{E}-03$ & $9.2927 \mathrm{E}-03$ & $5.7876 \mathrm{E}-02$ & $7.2478 \mathrm{E}-01$ & $7.0689 \mathrm{E}-01$ \\
\hline \multirow{2}{*}{ ABC } & \% Error (A) & $4.3953 \mathrm{E}-09$ & $1.0804 \mathrm{E}-07$ & $6.1911 \mathrm{E}-07$ & $4.7619 \mathrm{E}-07$ & $4.1335 \mathrm{E}-07$ \\
\cline { 2 - 7 } & \% Error (P) & $1.5648 \mathrm{E}-08$ & $2.5605 \mathrm{E}-08$ & $3.5256 \mathrm{E}-08$ & $7.2666 \mathrm{E}-07$ & $2.0764 \mathrm{E}-06$ \\
\hline \multirow{2}{*}{ SCA } & \% Error (A) & $9.0536 \mathrm{E}-03$ & $1.5421 \mathrm{E}-03$ & $5.5583 \mathrm{E}-01$ & $3.6819 \mathrm{E}-01$ & $2.5975 \mathrm{E}-01$ \\
\cline { 2 - 7 } & \% Error (P) & $6.8739 \mathrm{E}-03$ & $2.5684 \mathrm{E}-01$ & $2.1964 \mathrm{E}-01$ & $1.6104 \mathrm{E}+00$ & $7.7115 \mathrm{E}-01$ \\
\hline \multirow{2}{*}{ MFO } & \% Error (A) & $0.0000 \mathrm{E}+00$ & $0.0000 \mathrm{E}+00$ & $0.0000 \mathrm{E}+00$ & $0.0000 \mathrm{E}+00$ & $0.0000 \mathrm{E}+00$ \\
\cline { 2 - 7 } & \% Error (P) & $0.0000 \mathrm{E}+00$ & $0.0000 \mathrm{E}+00$ & $4.4212 \mathrm{E}-13$ & $0.0000 \mathrm{E}+00$ & $3.3277 \mathrm{E}-12$ \\
\hline \multirow{2}{*}{ TLBO } & \% Error (A) & $0.0000 \mathrm{E}+00$ & $0.0000 \mathrm{E}+00$ & $0.0000 \mathrm{E}+00$ & $0.0000 \mathrm{E}+00$ & $0.0000 \mathrm{E}+00$ \\
\cline { 2 - 7 } & \% Error (P) & $1.2434 \mathrm{E}-13$ & $0.0000 \mathrm{E}+00$ & $6.6317 \mathrm{E}-13$ & $1.1053 \mathrm{E}-12$ & $3.6711 \mathrm{E}-12$ \\
\hline \multirow{2}{*}{ WOA } & \% Error (A) & $4.0241 \mathrm{E}-02$ & $3.6869 \mathrm{E}-02$ & $7.8461 \mathrm{E}-01$ & $6.9755 \mathrm{E}-02$ & $4.1513 \mathrm{E}-02$ \\
\cline { 2 - 7 } & \% Error (P) & $2.74 \mathrm{E}-04$ & $3.08 \mathrm{E}-01$ & $6.97 \mathrm{E}-01$ & $8.65 \mathrm{E}-01$ & $4.61 \mathrm{E}-01$ \\
\hline
\end{tabular}

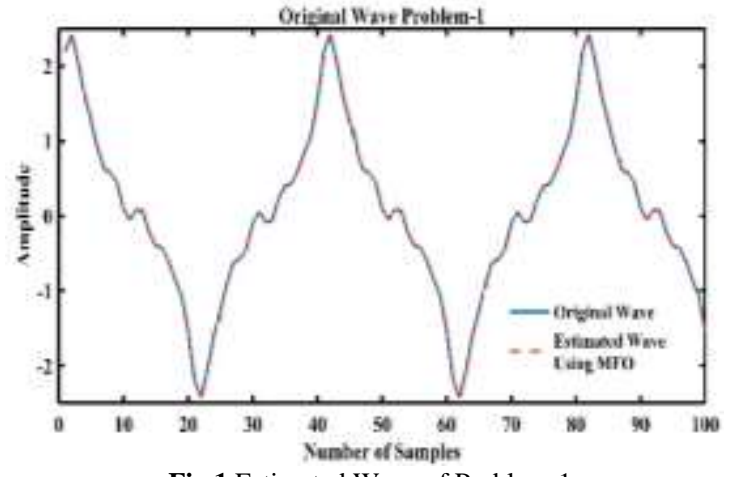

Fig.1 Estimated Wave of Problem-1

While the $\mathrm{ABC}$ algorithm provides an optimal value for minimum attribute. Table 2 represents estimated values of phase and amplitude components of power harmonics with the help of ABC, TLBO, GWO, SCA, MFO, and ASO. From these values, it is seen that $\mathrm{ABC}$, TLBO, and MFO provide an exact estimation of phase and amplitude components of power harmonics. On the basis of these estimated parameters, estimated wave is shown in figure 1. After estimation of phase and amplitude values, we calculated the \% error values of phase and amplitude, which are reported in table III. From this table 3 it is evident that MFO provides optimal \% error values of phase and amplitude components in comparison to ABC, TLBO, GWO, SCA, ASO. From these estimations, it is proved that $\mathrm{MFO}$ provides optimal solutions for harmonic estimator design problem-1. Figure 1 represents estimated wave, which is plotted with the help of original case 1 design problem and MFO estimated wave (because MFO provides optimal solution). This estimated wave represents that estimated and original waves are almost similar and aligned with each other.

Table 4 Result comparison of applied algorithms for Problem 2

\begin{tabular}{|c|c|c|c|c|}
\hline \multicolumn{5}{|c|}{ Estimated Results of Case-2 } \\
\hline WaveForms & \multicolumn{4}{|c|}{ X(b) } \\
\hline Parameters & Mean & Max & Min & SD \\
\hline GWO & $1.6958 \mathrm{E}-05$ & $4.3147 \mathrm{E}-05$ & $1.6641 \mathrm{E}-06$ & $1.0828 \mathrm{E}-05$ \\
\hline ABC & $1.0688 \mathrm{E}-12$ & $7.0908 \mathrm{E}-12$ & $5.8321 \mathrm{E}-14$ & $1.8723 \mathrm{E}-12$ \\
\hline SCA & $1.5323 \mathrm{E}-03$ & $2.2656 \mathrm{E}-03$ & $5.8772 \mathrm{E}-04$ & $4.7807 \mathrm{E}-04$ \\
\hline MFO & $7.6964 \mathrm{E}-06$ & $5.0000 \mathrm{E}-05$ & $2.6016 \mathrm{E}-16$ & $1.1350 \mathrm{E}-05$ \\
\hline TLBO & $7.2469 \mathrm{E}-29$ & $3.8229 \mathrm{E}-28$ & $1.3292 \mathrm{E}-30$ & $1.1179 \mathrm{E}-28$ \\
\hline WOA & $1.8795 \mathrm{E}-04$ & $2.9613 \mathrm{E}-04$ & $7.7877 \mathrm{E}-05$ & $6.8248 \mathrm{E}-05$ \\
\hline
\end{tabular}

\subsection{Design Problem-2}

For design problem-2 a waveform is used which is made up of sub, fundamental, $3^{\text {rd }}$, inter-1, inter-2, $5^{\text {th }}, 7^{\text {th }}$ and $11^{\text {th }}$ harmonics. This waveform helps to measure the amplitude and phase values of power harmonics. This design problem-2 is mathematically expressed as $X_{2}(b)$

$$
\begin{aligned}
& X_{2}(b)=\frac{101}{200} \times \sin \left(2 \pi f^{(s u b)} c+75\right)+ \\
& \frac{3}{2} \times \sin \left(2 \pi f^{(1)} c+80\right)+\frac{1}{2} \times \sin \left(2 \pi f^{(3)} c+60\right)+
\end{aligned}
$$

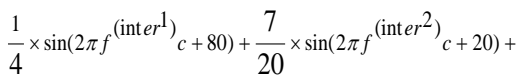

$$
\begin{aligned}
& \frac{1}{5} \times \sin \left(2 \pi f^{(5)} c+45\right)+\frac{3}{20} \times \sin \left(2 \pi f^{(7)} c+36\right)+\frac{1}{10} \times \sin \left(2 \pi f^{(11)} c+30\right)+ \\
& \frac{1}{2} \times \exp (-5 c)+\sigma
\end{aligned}
$$


like problem-1, we also calculate the mean, max, min, and SD attributes for problem-2 for 20 independent runs, which are reported in table 4 . From table 4 values, it is said that TLBO provides optimal results for all four attributes in comparison to $\mathrm{ABC}, \mathrm{GWO}, \mathrm{SCA}, \mathrm{MFO}$ and ASO.

Table 5 Parameters Analysis of Problem-2

\begin{tabular}{|c|c|c|c|c|c|c|c|c|c|}
\hline \multicolumn{10}{|c|}{ Parameter's Analysis of Problem-2 } \\
\hline Waveforms & Parameters & Sub & Fun & 3rd & Inter-1 & Inter-2 & 5th & 7th & 11th \\
\hline \multirow{3}{*}{$\begin{array}{c}\text { Actual } \\
\text { Waveform } \\
\text { Parameter's }\end{array}$} & $\mathbf{F}(\mathbf{H z})$ & 20 & 50 & 150 & 180 & 230 & 250 & 350 & 550 \\
\hline & $\mathbf{A}(\mathbf{V})$ & 0.505 & 1.5 & 0.5 & 0.25 & 0.35 & 0.2 & 0.15 & 0.1 \\
\hline & $P$ (deg.) & 75 & 80 & 60 & 65 & 20 & 45 & 36 & 30 \\
\hline \multirow{2}{*}{ GWO } & $\mathbf{A}(\mathbf{V})$ & 0.5044 & 1.4997 & 0.5000 & 0.2502 & 0.3497 & 0.199604399 & 0.150256311 & 0.099762264 \\
\hline & $P$ (deg.) & 74.9760 & 79.9956 & 60.0148 & 65.0394 & 20.0130 & 45.06166039 & 35.85965997 & 28.93271575 \\
\hline \multirow{2}{*}{$\mathbf{A B C}$} & $\mathbf{A}(\mathbf{V})$ & 0.5050 & 1.5000 & 0.5000 & 0.2500 & 0.3500 & 0.1999999957 & 0.150000047 & 0.100000097 \\
\hline & $P$ (deg.) & 75.0000 & 80.0000 & 60.0000 & 65.0000 & 20.0000 & 45.00000718 & 36.00005095 & 30.00003581 \\
\hline \multirow{2}{*}{ SCA } & $A(V)$ & 0.5030 & 1.4966 & 0.4989 & 0.2548 & 0.3497 & 0.196485727 & 0.148436815 & 0.098775402 \\
\hline & $P$ (deg.) & 74.8751 & 80.2915 & 59.2687 & 61.5970 & 19.1265 & 44.32344451 & 35.60125775 & 28.37118786 \\
\hline \multirow{2}{*}{ MFO } & $A(V)$ & 0.5050 & 1.5000 & 0.5000 & 0.2500 & 0.3500 & \begin{tabular}{|l|}
0.19999671 \\
\end{tabular} & 0.150494566 & 0.099984551 \\
\hline & $P$ (deg.) & \begin{tabular}{|l|}
75.0001 \\
\end{tabular} & 80.0000 & 59.9999 & 65.2500 & 19.9999 & 45.10013965 & 36.10003307 & 30.49975258 \\
\hline \multirow{2}{*}{ TLBO } & $\mathbf{A}(\mathbf{V})$ & 0.5050 & 1.5000 & 0.5000 & 0.2500 & 0.3500 & 0.2000 & 0.1500 & 0.1000 \\
\hline & $P$ (deg.) & 75.0000 & 80.0000 & 60.0000 & 65.0000 & 20.0000 & 45.0000 & 36.0000 & 30.0000 \\
\hline \multirow{2}{*}{ ASO } & $\mathbf{A}(\mathbf{V})$ & 0.4986 & 1.4998 & 0.5013 & 0.2501 & 0.3571 & 0.204765909 & 0.148497253 & 0.098863638 \\
\hline & $P$ (deg.) & 75.0406 & 80.0018 & 59.9199 & 64.2532 & 20.3189 & 44.93625847 & 36.37846001 & 29.58610299 \\
\hline
\end{tabular}

Table $6 \%$ Error Analysis of Problem-2

\begin{tabular}{|c|c|c|c|c|c|c|c|c|c|}
\hline \multicolumn{10}{|c|}{ \% Error Analysis of Problem-2 } \\
\hline $\begin{array}{l}\text { Wave } \\
\text { forms }\end{array}$ & Parameters & Sub & Fun & 3rd & Inter-1 & Inter-2 & 5th & 7th & 11th \\
\hline \multirow{2}{*}{$\begin{array}{l}\text { Actual } \\
\text { Signal }\end{array}$} & $\mathbf{A}(\mathbf{V})$ & 0.505 & 1.5 & 0.5 & 0.25 & 0.35 & 0.2 & 0.15 & 0.1 \\
\hline & P (deg.) & 75 & 80 & 60 & 65 & 20 & 45 & 36 & 30 \\
\hline $\mathbf{A B C}$ & $\begin{array}{c}\% \text { Error } \\
\text { (A) }\end{array}$ & $5.0554 \mathrm{E}-06$ & $1.2539 \mathrm{E}-06$ & $1.0576 \mathrm{E}-05$ & 2.7407E-05 & $9.6211 \mathrm{E}-06$ & $2.1254 \mathrm{E}-05$ & $3.1043 \mathrm{E}-05$ & $9.6804 \mathrm{E}-05$ \\
\hline \multirow{2}{*}{ TLBO } & $\begin{array}{l}\% \text { Error } \\
\text { (A) }\end{array}$ & $1.9786 \mathrm{E}-13$ & $0.0000 \mathrm{E}+00$ & $0.0000 \mathrm{E}+00$ & $3.9968 \mathrm{E}-13$ & $0.0000 \mathrm{E}+00$ & $0.0000 \mathrm{E}+00$ & $6.6613 \mathrm{E}-13$ & $2.0817 \mathrm{E}-13$ \\
\hline & $\begin{array}{l}\% \text { Error } \\
(\mathrm{P})\end{array}$ & $0.0000 \mathrm{E}+00$ & $2.4869 \mathrm{E}-13$ & $4.9738 \mathrm{E}-13$ & $6.1216 \mathrm{E}-13$ & 3.4994E-12 & $2.0053 \mathrm{E}-12$ & $3.0593 \mathrm{E}-12$ & $2.9961 \mathrm{E}-12$ \\
\hline \multirow{2}{*}{ SCA } & $\begin{array}{l}\text { \% Error } \\
\text { (A) }\end{array}$ & $3.9916 \mathrm{E}-01$ & $2.2762 \mathrm{E}-01$ & $2.1795 \mathrm{E}-01$ & $1.9208 \mathrm{E}+00$ & 9.8913E-02 & $1.7571 \mathrm{E}+00$ & $1.0421 \mathrm{E}+00$ & $1.2246 \mathrm{E}+00$ \\
\hline & $\begin{array}{l}\text { \% Error } \\
(\mathrm{P})\end{array}$ & $1.6659 \mathrm{E}-01$ & $3.6437 \mathrm{E}-01$ & $1.2188 \mathrm{E}+00$ & $5.2354 \mathrm{E}+00$ & $4.3675 \mathrm{E}+00$ & $1.5035 \mathrm{E}+00$ & $1.1076 \mathrm{E}+00$ & $5.4294 \mathrm{E}+00$ \\
\hline \multirow{2}{*}{ MFO } & $\begin{array}{c}\% \text { Error } \\
\text { (A) }\end{array}$ & $2.6659 \mathrm{E}-06$ & $1.8988 \mathrm{E}-07$ & 6.2181E-05 & $3.7195 \mathrm{E}-03$ & 8.4124E-05 & 1.6449E-03 & $3.2971 \mathrm{E}-01$ & $1.5449 \mathrm{E}-02$ \\
\hline & $\begin{array}{l}\% \text { Error } \\
(\mathrm{P})\end{array}$ & $1.0721 \mathrm{E}-04$ & $1.5720 \mathrm{E}-05$ & $9.1368 \mathrm{E}-05$ & $3.8466 \mathrm{E}-01$ & 4.2830E-04 & 2.2253E-01 & $2.7787 \mathrm{E}-01$ & $1.6658 \mathrm{E}+00$ \\
\hline \multirow{2}{*}{ ASO } & $\begin{array}{c}\% \text { Error } \\
\text { (A) }\end{array}$ & $1.2771 \mathrm{E}+00$ & $1.1866 \mathrm{E}-02$ & 2.6202E-01 & 5.3643E-02 & $2.0199 \mathrm{E}+00$ & $2.3830 \mathrm{E}+00$ & $1.0018 \mathrm{E}+00$ & $1.1364 \mathrm{E}+00$ \\
\hline & $\begin{array}{c}\% \text { Error } \\
(\mathrm{P})\end{array}$ & $5.4156 \mathrm{E}-02$ & $2.2554 \mathrm{E}-03$ & $1.34 \mathrm{E}-01$ & $1.1578 \mathrm{E}+00$ & $1.5901 \mathrm{E}+00$ & $1.4228 \mathrm{E}-01$ & $1.0554 \mathrm{E}+00$ & $1.3800 \mathrm{E}+00$ \\
\hline
\end{tabular}




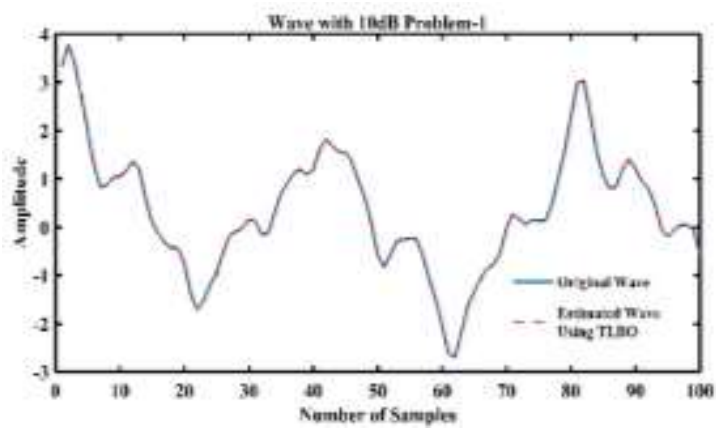

Figure 2 Estimated Wave of Problem-2

Table 5 represents estimated values of phase and amplitudecomponents of power harmonics with the help of ABC, TLBO, GWO, SCA, MFO, and ASO. From these values, it is seen that TLBO, and MFO provide an exact estimation of phase and amplitude components of power harmonics. By using these values we design an estimated wave shown in figure 2. After estimation of phase and amplitude values, we calculated the $\%$ error values of phase and amplitude, which are reported in table VI. From this table 6 it is evident that TLBO provides minimum $\%$ error values of phase and amplitude components in comparison to $\mathrm{ABC}, \mathrm{GWO}, \mathrm{SCA}, \mathrm{MFO}$ and ASO. From these estimations, it is proved that TLBO provides optimal solutions for harmonic estimator design problem-2. Fig 2 represents estimated wave, which is plotted with the help of original case 1 design problem and TLBO estimated wave (because TLBO provides optimal solution). This estimated wave represents that estimated and original waves are almost similar and aligned with each other.

\section{CONCLUSION}

Accurate phase and amplitude parameter estimation are important for the design of harmonic filters. In this work, we have provided a comparative study of the harmonic estimators that are designed with the application of ABC, TLBO, GWO, SCA, MFO, and ASO algorithm.

From this analysis it is observed that MFO provides optimal solutions when the sub and inter- harmonics components are absent while TLBO provides optimal solutions in the presence of sub and interharmonics components.

\section{REFERENCES}

[1] Z.M. Hafed and M.D Levine. Face recognition using discrete cosine transform. Journal of Computer Vision, 43(3):167-188, 2001

[2] Zhao. W., Chellappa. R., Phillips. P.J. and Rosenfeld. A. (2003) 'Face Recognition: A Literature Survey' Journal of ACM Computing Surveys (CSUR), Vol. 35, No. 4, December, pp. 399- 458.

[3] Hazim. K.E. and Rainer.S. (2006) 'Local Appearance based Face Recognition Using Discrete Cosine Transform' 13th European Signal Processing Conference (EUSIPCO).

[4] Tudor. B. (2010) 'Gabor or Filter-based Face Recognition
Technique' Proceeding of The Romanian Academy, Series A, Vol.11, No. 3, pp. 277-283.

[5] W. Hwang, H. Wang, H. Kim, S. Kee and J. Kim, "Face Recognition System Using Multiple Face Model of Hybrid Fourier Feature Under Uncontrolled Illumination Variation," in IEEE Transactions on Image Processing, vol. 20, no. 4, pp. 1152-1165, April 2011, doi 10.1109/TIP.2010.2083674

[6] WeiFeng Liu and ZengFu Wang. Face recognition based on fusion of multiple Gabor features. In IEEE International conference on Pattern Recognition.IEEE, 2006.

[7] Fenguin Chen Zhiliang Wang Zhengguang Xu Jianng Xiao and Guojiang Wang. Face recognition using wavelet transform and neural network ensemble. In Internation Symposium on Intelligent Information Technology Application, volume 24, pages 871-875. IEEE, 2008.

[8] Meihua Wang, Hong Jiang and Ying Li, "Face recognition based on DWT/DCT and SVM," 2010 International Conference on Computer Application and System Modeling (ICCASM 2010), Taiyuan, 2010, pp. V3-507-V3-510.

[9] Xiaoli Li Qiuqi Ruan Chengxiong Ruan, "Facial Expression Recognition with Local GaborFilters", International conference, IEEE, 2010.

[10] Guoqiang Wang and Zongying Ou, "Face Recognition Based on Image Enhancement and Gabor Features," 2006 6th World Congress on Intelligent Control and Automation, Dalian, 2006, pp. 9761-9764, doi: 10.1109/WCICA.2006.1713900.

[11] S. Nazari, M.S. Moin, "Face recognition and local Gabor features", in international conference on electrical engineering (ICEE), pp 1-4, IEEE, 2013.

[12] S. Ajitha, A. Annis Fathima, V. Vaidehi, M. Hemalatha and R. Karthigaiveni, "Face recognition system using Combined Gabor Wavelet and DCT approach," 2014 International Conference on Recent Trends in Information Technology, Chennai, 2014, pp. 1-6, doi: 10.1109/ICRTIT.2014.6996156.

[13] https://www.mathworks.com/help/images/discrete-cosinetransform.html

[14] S. Nasr, K. Bouallegue, M. Shoaib and H. Mekki, "Face recognition system using bag of features and multi-class SVM for robot applications," 2017 International Conference on Control, Automation and Diagnosis (ICCAD), Hammamet, 2017, pp. 263-268, doi: 10.1109/CADIAG.2017.8075668.

[15] S. M. Jaisakthi and C. Aravindan, "Face detection based on eigenfaces and legendre moments," TENCON 2009 - 2009 IEEE Region 10 Conference, Singapore, 2009, pp. 1-5, doi: 10.1109/TENCON.2009.5396153.

\section{APPENDIX}

Table 7 Data Set for Problem-1

\begin{tabular}{|c|c|c|c|c|c|c|}
\hline \multicolumn{7}{|c|}{ Data of Problem-1 } \\
\hline Waveforms & Parameters & Fun & 3rd & 5th & 7th & 11th \\
\hline \multirow{2}{*}{$\begin{array}{c}\text { Actual } \\
\text { Waveform }\end{array}$} & F (Hz) & 50 & 150 & $\mathbf{2 5 0}$ & 350 & 550 \\
\cline { 2 - 7 } Parameter's & A (V) & 1.5 & 0.5 & 0.2 & $\mathbf{0 . 1 5}$ & $\mathbf{0 . 1}$ \\
\cline { 2 - 7 } & P (deg.) & $\mathbf{8 0}$ & 60 & 45 & 36 & 30 \\
\hline
\end{tabular}

Table 8 Data Set for Problem-2

\begin{tabular}{|c|c|c|c|c|c|c|c|c|c|}
\hline \multicolumn{10}{|c|}{ Data of Problem-2 } \\
\hline Wav & $\begin{array}{c}\text { Parameter } \\
\text { s }\end{array}$ & Sub & Fun & \begin{tabular}{|c|}
$3 r$ \\
$d$
\end{tabular} & \begin{tabular}{|c|} 
Inter \\
-1
\end{tabular} & \begin{tabular}{|c|} 
Inter \\
-2 \\
\end{tabular} & 5 th & 7th & $\begin{array}{c}11 t \\
\text { h }\end{array}$ \\
\hline \multirow{3}{*}{$\begin{array}{c}\text { Actual } \\
\text { waveform } \\
\text { Parameter' } \\
\text { s }\end{array}$} & $(\mathbf{H z})$ & 0 & 50 & $\begin{array}{c}15 \\
0 \\
\end{array}$ & 180 & 230 & \begin{tabular}{|c|}
25 \\
0
\end{tabular} & 350 & 550 \\
\hline & $\mathbf{A}(\mathbf{V})$ & $\begin{array}{c}0.50 \\
5 \\
\end{array}$ & $\begin{array}{l}1 . \\
5\end{array}$ & 0.5 & 0.25 & 0.35 & 0.2 & $\begin{array}{c}0.1 \\
5 \\
\end{array}$ & 0.1 \\
\hline & $\mathbf{P}$ (deg.) & 75 & 80 & 60 & 65 & 20 & 45 & 36 & 30 \\
\hline
\end{tabular}

